Int. J. Electrochem. Sci., 12 (2017) $6545-6556$

\title{
Fabrication of N-doped Carbon Derived from poly(acrylonitrile)-ionic Liquid Copolymer and Application in Lithium Ion Batteries
}

\author{
Lei Wang ${ }^{1}$, Fuliang Zhu ${ }^{1}$, Jun Xia ${ }^{1}$, Gongrui Wang ${ }^{1}$, Yanshuang Meng ${ }^{1,3, *}$, Yue Zhang ${ }^{2, *}$ \\ ${ }^{1}$ School of Materials Science and Engineering, Lanzhou University of Technology, Lanzhou 730050, \\ China \\ ${ }^{2}$ Department of Mechanical and Industrial Engineering, Texas A\&M University-Kingsville, \\ Kingsville, Texas, 78363, USA \\ ${ }^{3}$ State Key Laboratory of Advanced Processing and Recycling of Non-ferrous Metals, Lanzhou \\ 730050, China \\ *E-mail address: mengyanshuang@163.com, yue.zhang@tamuk.edu
}

doi: $10.20964 / 2017.07 .78$

Received: 12 April 2017 / Accepted: 19 May 2017 / Published: 12 June 2017

Nitrogen-doped carbon materials have been prepared by soap-free emulsion with poly(acrylonitrile) (PAN) and poly(acrylonitrile)-ionic liquid copolymer (PAN-PIL) as carbon sources. The carbonized PAN-PIL (CPAN-PIL) shows a higher nitrogen content (6.80 at.\%.) than the carbonized PAN (CPAN) (2.32 at.\%). The ionic liquid copolymer introduced graphitic nitrogen to CPAN-PIL, which was not observed in CPAN. The high nitrogen content and graphic nitrogen improved the electrical conductivity and increased the number of active sites. Therefore, CPAN-PIL displayed a specific capacity of $381 \mathrm{mAh} \mathrm{g}^{-1}$ after 50 cycles, which is $23 \%$ higher than the specific capacity of CPAN.

Keywords: Poly(acrylonitrile)-ionic liquid copolymer; N-doped carbon; Lithium ion batteries

\section{$\underline{\text { FULL TEXT }}$}

(C) 2017 The Authors. Published by ESG (www.electrochemsci.org). This article is an open access article distributed under the terms and conditions of the Creative Commons Attribution license (http://creativecommons.org/licenses/by/4.0/). 